\title{
Saeb e Qualidade de Ensino: algumas questões
}

\author{
ADRIANA BAUER \\ Mestranda do Programa de Pós-graduação da USP \\ dri_bauer@yahoo.com.br \\ VANDRÉ GOMES DA SILVA \\ Mestre e doutorando em Educação pela Universidade de São Paulo \\ vandregs@ig.com.br
}

\begin{abstract}
Resumo
Este trabalho tem como objetivo discutir o conceito de qualidade que permeia o Sistema de Avaliação da Educação Básica (Saeb) a partir de duas perspectivas: os Parâmetros Curriculares Nacionais que o subsidiam e a discussão a propósito da disseminação de resultados e seus eventuais impactos. Em um primeiro momento procura-se problematizar o uso dos PCN's como fundamento da construção das Matrizes Curriculares dessa avaliação, relacionando-os com o debate acerca de suas repercussões na prática escolar e, conseqüentemente, na qualidade do ensino. Nesse sentido, pondera-se sobre a questão dos usos dos resultados da avaliação e a necessidade de uma melhor definição de seus interlocutores. Por fim, procura-se esclarecer e problematizar o sentido e o significado da qualidade de ensino que o Saeb pretende medir.

Palavras-chave: Saeb, qualidade de ensino, Parâmetros Curriculares Nacionais, sistema de avaliação, políticas educacionais.
\end{abstract}

\section{Resumen}

Este trabajo pretende cuestionar el concepto de cualidad en el Saeb - Sistema de Evaluación de la Educación Básica desde dos perspectivas: los PCN - Parámetros Curriculares Nacionales - que los subsidian y los eventuales impactos surgidos del resultado de la diseminación de las evaluaciones. En un primer momento, se busca discutir el uso de los PCN como fundamento de la construcción de las Matrices Curriculares a la vez que se los relaciona con el debate surgido de las repercusiones en la práctica escolar $\mathrm{y}$, en consecuencia, en la cualidad de la enseñanza. Trata de la cuestión de los usos de los resultados de la evaluación y la necesidad de una mejor definición de sus interlocutores. Por fin, se busca aclarar y discutir el sentido y el significado de la cualidad de enseñanza que el Saeb pretende medir.

Palabras-clave: Saeb, cualidad de enseñanza, Parámetros Curriculares Nacionales, sistema de evaluación, políticas educativas. 


\begin{abstract}
This article discusses the concept of quality in the National Basic Education Evaluation System (Saeb) in two parts: the adoption of the National Curriculum Parameters and the impact of the evaluation's results. By analyzing parameters for the curricula, this article discusses their influence on school practices and education quality. Results of the evaluation are covered in the text.

Key words: National Basic Education Evaluation System, education quality, National Curriculum Parameters, large-scale assessment, educational policies.
\end{abstract}


A constituição de sistemas de avaliação tem sido explicada como um dos pontos focais de uma política de condução dos assuntos de Estado, cujos reflexos aparecem na forma de organizar e gerir os sistemas educacionais, não só no Brasil como em vários países. Embora o aprofundamento da discussão sobre o papel que as avaliações sistêmicas desempenham em uma dada política educacional constitua um exercício interessante e, mesmo, necessário, a intenção do presente artigo, mais modesta, é a de analisar o conceito de qualidade subjacente ao Sistema de Avaliação do Ensino Básico (Saeb) a partir de duas perspectivas: as matrizes curriculares que subsidiam e norteiam a avaliação e os eventuais usos de seus resultados.

Isso porque um dos objetivos principais do Saeb, senão o mais importante, é o de ser um sistema de aferição da qualidade do ensino ministrado nas escolas brasileiras. A medida de qualidade pressupõe determinados parâmetros, nem sempre explícitos ou destacados quando da discussão de uma avaliação sistêmica. A partir da apreciação da produção teórica realizada em torno de avaliações em larga escala, divulgada no Brasil, acreditamos que o debate sobre qualidade requer aprofundamento, demandando inclusive investigações empíricas que abordem questões que vêm sendo apontadas por estudos de caráter ainda exploratório. Além disso, a discussão dos eventuais usos dos resultados da avaliação merece especial destaque uma vez que visam a orientar e a direcionar uma determinada visão de escola e, conseqüentemente, da qualidade de ensino, cujo parâmetro, como poderemos ver, é bastante discutível e nãoconsensual.

As perspectivas de análise do Saeb pautadas em suas matrizes curriculares e em eventuais usos e impactos de seus resultados, embora estejam presentes, em alguma medida, no debate que vem sendo feito a propósito da sua constituição, implementação e divulgação, não raro perdem espaço e importância em favor de uma abordagem conjuntural mais ampla.

Evidentemente, a análise do contexto político e econômico pode contribuir para compreender o processo de formulação e implementação do Saeb. Não resta dúvida de que perspectivas de análise calcadas em conceitos mais ou menos explicitados, como "neoliberalismo" e "globalização da economia", têm sido trabalhadas quase à exaustão, acarretando, inclusive, a constituição de um discurso, muitas vezes, monolítico.

Para ficarmos em um exemplo apenas, destacamos a cantilena que atribui, por exemplo, ao Banco Mundial a influência sobre a formulação e 
implementação de determinadas políticas. Referindo-se à questão da formação de professores, Torres declara:

"Esta ênfase na capacitação em serviço (e o correspondente abandono da formação inicial) está fortemente vinculada ao Banco Mundial, a suas recomendações de política e o seu financiamento nos países em desenvolvimento." (1998, p. 176)

Muitas outras passagens de semelhante teor serviriam de ilustração para esse tipo de visão. Evidentemente, não desconsideramos o fato de que há uma relação absolutamente identificável entre esses órgãos internacionais e as características que têm estado presentes na gestão de políticas públicas em educação no Brasil. Aliás, não seria exagero identificar, a partir de 1995, certa movimentação da equipe do Instituto Nacional de Estudos e Pesquisas Educacionais (Inep) na busca de um endosso político do Banco Mundial para a reformulação do Saeb, que se traduziria em benefícios, sobretudo financeiros, proporcionados por este órgãoํㅗ (Bonamino, 2002, p. 101).

Contudo, sem negar a influência que os empréstimos e as diretrizes do Banco Mundial têm sobre a educação brasileira, parece haver uma tendência de supervalorizar a influência de órgãos internacionais, como o Banco Mundial, acerca do planejamento educacional brasileiro, dando, não raro, a impressão de que os gestores não passam de meros executores de propostas absolutamente prontas e acabadas, independentemente de seus interesses políticos ou do lugar onde tais propostas deveriam ser implementadas.

Muitos estudos fazem uma simplificação dessas relações estabelecidas entre determinados organismos internacionais e a gestão de políticas nacionais. Para os autores, não há um "alinhamento incondicional entre as políticas produzidas no contexto das instituições multilaterais e as políticas nacionais que aceitam e ratificam suas orientações em função das necessidades dos recursos que os acompanham" (Tommasi, Warde, Haddad, 1998, p. 44).

1 A idéia de formulação de um sistema de avaliação da Educação Básica começa a se delinear já em 1988, por meio do Sistema Nacional de Avaliação do Ensino Público de $1^{\circ}$ Grau (Saep), que fazia parte de um acordo entre o MEC e o Banco Mundial. Aliás, no que se refere à influência de organismos internacionais sobre o modelo de avaliação adotado, Bonamino (2002), ao contextualizar esse modelo de avaliação desvelando suas referências e apontando algumas de suas tendências, ressalta que nos primeiros ciclos do Saeb (1990 e 1993) foram propostas avaliações cuja estrutura era bastante distinta da defendida pelo Bird, naquele momento. 
De fato, negar que os responsáveis pelas políticas educacionais, em nível nacional ou local, assumem um papel importante em seu direcionamento, por serem obrigados a prestar contas aos organismos internacionais e, portanto, serem obrigados a "obedecer" todas as orientações recebidas ou prescrições feitas, parece ser uma visão um tanto exagerada. Mesmo porque, o que alguns interpretam como "obediência" talvez possa ser melhor compreendido como uma relação de reciprocidade entre projetos políticos comuns.

Nessa perspectiva, parece ser comum que os contornos teóricos que animam uma determinada avaliação sistêmica, seus objetivos declarados e implícitos e seus eventuais reflexos na organização de um sistema de ensino, não raro, perdem espaço para a denúncia de uma eventual relação de causa-efeito de órgãos internacionais na condução dos negócios de Estado.

Em que pese a conjuntura política que permeia a avaliação, o olhar intrínseco ao sistema pode revelar aspectos importantes que escapam a uma análise que localiza o Saeb apenas como um reflexo das reformas educacionais que foram implementadas, notadamente, a partir de 1995. Nesse sentido, dois desses aspectos chamam especial atenção: as matrizes curriculares que norteiam essa avaliação e induzem um determinado parâmetro de qualidade e seus eventuais impactos nos sistemas escolares brasileiros.

\section{PCN' S, SAEB E A AUTONOMIA ESCOLAR}

Uma das questões centrais que merece análise, quando se discutem as possíveis implicações do Saeb, refere-se às matrizes curriculares que servem de base para a elaboração das avaliações. Entretanto, não se pode relacionar a elaboração e implementação dos Parâmetros Curriculares Nacionais² (PCN's) à constituição de um sistema nacional de avaliação de forma interdependente e direta.

A partir do histórico do Saeb, percebe-se que a opção por uma determinada perspectiva metodológica que orienta a avaliação e os critérios de definição de níveis de aprendizagem, concebidos a partir dos Parâmetros Curriculares Nacionais e de sua explicitação através das

2 Os Parâmetros Curriculares Nacionais (PCN's) foram elaborados pelo Ministério da Educação com o propósito de apontar diretrizes para o trabalho pedagógico realizado na Educação Básica. Seu objetivo, bastante amplo, é o de subsidiar as discussões pedagógicas e a elaboração dos projetos educacionais, bem como o planejamento das aulas e o processo de reflexão sobre as práticas docentes. 
Matrizes Curriculares de Referência, foi sendo introduzida aos poucos, até porque o Saeb é anterior à elaboração dos PCN's. Contudo, mesmo sendo políticas distintas, tornaram-se complementares à medida que, atualmente, o Saeb - e outros tantos sistemas de avaliação regionais nele inspirados supõe que as escolas devam adotar as diretrizes presentes nestes parâmetros e em suas matrizes de referência.

Embora o desenho do Saeb tenha sofrido reformulações desde seus primeiros ciclos, algumas dessas mudanças ganham destaque especial, como, por exemplo, a introdução, em 1995, da ferramenta metodológica da Teoria de Resposta ao Item (TRI), fato que, anterior à elaboração dos PCN's, modificou sobremaneira a forma de formulação e aplicação das provas e interpretação dos resultados.

A partir daí se modificam as orientações das matrizes que subsidiam e norteiam o que e como será aferido o nível de aprendizagem dos alunos. Essas orientações, introduzidas na avaliação a partir de 1997, procuraram atrelar, de certa forma, as características e pretensões do Saeb às novas abordagens e reformas curriculares que se implementavam na época de sua elaboração.

Nos termos de sua formulação, as matrizes curriculares de referência do Saeb são construídas para aferir:

"[...] as competências cognitivas dos alunos brasileiros a partir de seus desempenhos reais em provas elaboradas segundo parâmetros consensuais, tanto conseqüentes da reflexão teórica sobre a estrutura da ciência e sua correspondente adequação às estruturas de conhecimento como advindos de uma permanente consulta nacional sobre os conteúdos praticados, indicados pelas escolas brasileiras em estreita correlação com as diretrizes dos Parâmetros Curriculares Nacionais e os textos de referência da reforma do Ensino Médio." (Brasil, 1999, p. 7, grifos nossos)

Não são poucos os que acreditam que, ao se utilizar exclusivamente de um determinado referencial curricular com as características dos PCN's, o Saeb poderia condicionar uma transformação radical do currículo escolar, induzindo a um enrijecimento das atividades pedagógicas das escolas (Sousa, 2003).

Não se pretende fazer, aqui, uma crítica ao uso de parâmetros comuns na escola, pois acreditamos que estes são necessários para determinar um currículo mínimo a ser trabalhado em nível nacional, visando a contribuir, 
de certa forma, para um patamar aceitável e desejável de eqüidade do ensino ${ }^{3}$.

Dependendo do grau de conformidade das escolas aos PCN's, especificamente, pode ocorrer o endosso da generalização de um discurso pedagógico totalizante que, em sua formulação, determina a aplicação e execução de uma proposta que supostamente seria mais apropriada para nortear a busca pela qualidade de ensino. Tal pretensão, tendo em vista as diretrizes curriculares que norteiam o Saeb, não é trivial. Embora seja bastante desejável e legalmente obrigatório garantir a "eqüidade de ensino" não se pode perder de vista que as unidades e sistemas escolares diferem muito entre si, demandando práticas escolares peculiares.

Estudos e pesquisas empíricas que tivessem como alvo esse objeto de estudo seriam de extremo interesse. Mesmo porque, como nos lembra Azanha:

"[...] sabe-se que é no interior das salas de aula que se decide o destino de políticas e reformas educacionais. [...] A trajetória de reformas desde as decisões politicas que as instituem legalmente, passando pelas providências técnico-administrativas de vários níveis que as regulamentam, até as práticas escolares que deveriam implantá-las, é ainda um território não devassado pela pesquisa educacional." (Azanha, 2001, p.26)

Chama a atenção, também, o fato dos termos em que são formulados os PCN's e as Matrizes Curriculares se expressarem em uma linguagem, ao mesmo tempo, simplista e bastante discutível. Talvez, algo que seja diretamente proporcional à visão bastante impressionista, mas não destituída de interesse, que Torres possui desse "curriculês". A autora, ao chamar a atenção para o caráter de certas reformas educacionais, afirma:

\footnotetext{
${ }^{3}$ Não se trata de defender a proposta em voga hoje, que são os PCN's, mas sim salvaguardar uma idéia: a existência de parâmetros curriculares que norteiem, em linhas gerais, as prioridades a serem consideradas no trabalho pedagógico das unidades escolares. Nesse sentido, o estabelecimento de um parâmetro curricular não significa, necessariamente, prescrever determinadas práticas e concepções que, em sua formulação, são herméticas e exclusivas, como as que encontramos nos PCN's, tampouco a proposição de uma lista exaustiva de conteúdos escolares a serem ensinados. De qualquer forma, divergimos de certas posições, por assim dizer relativistas, em relação à questão, como, por exemplo: “Dessa forma, a pretensão a um projeto nacional configura-se como inviável, não porque vivemos em um país de dimensões continentais, mas porque o próprio processo de elaboração curricular só pode ser pensado em uma dinâmica constante de construção e reconstrução que se inviabiliza, quando se cristaliza em propostas como a dos Parâmetros" (Santos, 2002, p. 355).
} 
"O curioso é que, com essa linguagem obtusa e cerrada, pretende-se convocar a consulta nacional e a participação do professorado e da opinião pública em geral. É claro que, se o professor não entende o documento, cala-se, porque seu ofício é entender, é saber (...) O curriculês é uma linguagem inventada pelos curriculistas $e$ os reformadores de currículo para que ninguém os entenda e, portanto, não se possa discutir o que eles expõem. É toda uma maneira de dizer e de comunicar 'à prova de' professores, pais de família e o grosso da população. Não obstante, é sobre esta base que se pretendem montar a participação e até a consulta e a construção de consensos, hoje tão na moda no jargão educativo." (Torres, 1998, p. 181-182)

De qualquer forma, ao descrever sinteticamente "as tendências pedagógicas da educação" no Brasil, os autores dos PCN's situam-no como a possibilidade de superação das mesmas, julgando-as insuficientes para orientar as práticas pedagógicas das escolas. Defendem, assim, de forma explícita, a concepção construtivista de ensino e aprendizagem, considerando-a mais adequada para suprir as necessidades do trabalho e demandas escolares. Não resta dúvida de que os PCN's renegam as propostas curriculares dos Estados, estas, encaradas, via de regra, como descrições de práticas escolares então realizadas e que em sua maioria estariam pautadas em uma ou outra dessas "tendências pedagógicas". Porém, já há aqui um grave problema: não se pode deduzir que tais propostas estaduais possam descrever fidedignamente o currículo e as formas de ensino praticadas nas escolas, nos diferentes Estados (Azanha, 2001, p. 26). Propostas curriculares se organizam a partir de discursos programáticos e visam a nortear a ação e não a descrição de uma dada realidade.

Nesses termos, a proposta dos PCN's, tal como se encontra, pressupõe a adoção de uma perspectiva metodológica em contraposição a outras existentes, indo de encontro, inclusive, a uma prerrogativa da LDB e da Constituição Nacional e ferindo o princípio da autonomia escolar, fato este agravado pela sua influência sobre as Matrizes Curriculares do Saeb:

"Embora o texto dos PCN refira-se a uma 'integração com a experiência educacional já realizada pelos Estados e Municípios' e à possibilidade de adaptações pelas Secretarias de Educação, é claro que a própria iniciativa ministerial implica a expectativa de uma profunda alteração da situação atual, com a adoção de novas diretrizes e de uma nova ordenação curricular a partir das posições e sugestões preparadas. Ora, na atual Constituição Federal, é dos Estados e Municípios a competência de organização de seus próprios sistemas de ensino, respeitadas as diretrizes e bases da educação nacional. O Artigo 210 da Constituição refere-se apenas a 'conteúdos mínimos' para o ensino fundamental, mas a lei $n^{\circ}$ 9.131, que criou o Conselho Nacional de Educação, ampliou a expressão constitucional para 'diretrizes curriculares' a serem propostas pelo MEC. Nessa alteração, que aumenta o poder central, há uma evidente diminuição do grau de autonomia de Estados e Municípios. (Azanha, 2001, p. 31) 
Pode uma proposta metodológica ser considerada mais adequada para a organização da educação do Brasil, já que tanto a constituição como a própria LDB faculta às escolas e professores: "pluralismo de idéias $e$ concepções pedagógicas?" Que precedentes legais e éticos tal postura pode abrir? Mais ainda: será essa uma questão de menor importância, haja vista a pouca ou nenhuma atenção que essa perspectiva adquire no debate do Saeb?

Ainda assim pode-se argumentar que, por seu caráter amostral, o Saeb não teria esse poder de pressão sobre os currículos e as práticas escolares. Porém, como já mencionado, deve-se lembrar que muitos dos sistemas de avaliações, em nível estadual e municipal, com caráter censitário, são idealizados a partir da experiência nacional, podendo transferir os pressupostos e determinados aspectos metodológicos - como o uso da Teoria da Resposta ao Item, segundo as matrizes do sistema nacional para esses sistemas regionais.

A título de exemplo, nos remetemos a um estudo empírico que identifica um certo impacto de um sistema de avaliação estadual, no caso o sistema de Avaliação do Rendimento Escolar do Estado de São Paulo - o Saresp. Esse estudo, dentre outras coisas, analisa uma escola que procura se preparar para o Saresp, preocupada com os resultados que podem obter no exame:

"O chamado "provão" (designação dos professores ao Saresp) adquiriu nesta escola uma função muito específica, que se sobrepõe à função de diagnóstico, tornando-se preparação para a prova do Saresp. À medida em que a avaliação do Saresp veio se impondo como referência para as escolas, estas foram se preocupando, cada vez mais, com os resultados obtidos." (Arcas, 2003, p. 3)

Ainda que não se vincule diretamente ao Saeb, a análise de um dos impactos do sistema paulista parece ser interessante não por generalizar as conclusões e estendê-las ao Saeb, o que seria um despropósito a começar pelo caráter censitário daquela e recorte amostral desta, mas para chamar a atenção para eventuais desdobramentos de um sistema de avaliação nas unidades escolares a que se destinam.

Mesmo que o Saeb não tenha um impacto direto sobre as escolas, mas sim sobre os sistemas de ensino, uma vez que trabalha com amostras de escolas, parece imprescindível levar em conta os possíveis impactos de um sistema de avaliação, principalmente quando surgem propostas de 
universalização desse sistema, como as divulgadas no primeiro semestre de $2004 .^{4}$

\section{SAEB: DISSEMINAÇÃO E USO DOS RESULTADOS}

Uma das críticas que vêm sendo feitas ao Saeb refere-se à divulgação dos resultados da avaliação para os diversos grupos da sociedade, principalmente para aqueles que são diretamente responsáveis pelo ensino, ou seja, os professores, coordenadores, diretores e dirigentes regionais.

Dessa forma, alguns autores têm chamado a atenção para o fato de que os resultados da avaliação, tanto os que se referem ao rendimento dos alunos, quanto as análises realizadas a partir dos questionários que são aplicados, por serem demasiadamente técnicos e complexos, trazem poucas informações que possam servir de subsídio para uma discussão sobre a prática pedagógica. Nesse sentido, não se potencializariam as reflexões que poderiam ocorrer nas escolas, gerando pouca (ou nenhuma) mudança no seu dia-a-dia, não sendo implementadas "medidas derivadas da análise dos resultados coletados" (Locatelli, 2002, p. 6). Como explicita Vianna:

"O grande problema do Saeb é que os seus resultados não chegam à escola e nem aos professores, não gerando, por conseguinte, qualquer impacto no sistema de ensino. Podem dar margem a pesquisas, muitas de grande sofisticação estatística, e importantes do ponto de vista científico, cujos resultados não se traduzem em ações pelos professores." (Vianna, 2002, p. 136)

Para José Francisco Soares, o Saeb deveria ser mais conhecido e analisado, inclusive pelo meio acadêmico. Esse autor, contudo, acredita que os dados produzidos pelo sistema, mesmo não sendo pensados para iluminar a tomada de decisões em cada escola, deveriam chegar ao professor. Segundo ele, "os resultados do Saeb não chegam ao professor naquilo que é importante para a sua prática pedagógica. Embora o interlocutor privilegiado do Saeb não seja o professor, seus resultados têm de chegar mais à escola" (Soares, 2002, p. 152).

\footnotetext{
4 Referimo-nos à possibilidade de tornar o Saeb censitário, aventada a partir da declaração do Exmo. Sr. Presidente Luiz Inácio Lula da Silva no início de 2004. Tal declaração causou certa polêmica no meio acadêmico que foi acirrada quando o MEC anunciou a intenção de universalizar o Saeb. A impossibilidade de o Inep operacionalizar essa avaliação fez com que fosse formulada uma nova proposta: a universalização somente para a avaliação da 2a série do Ensino Fundamental (Góis, 2004).
} 
Outros especialistas em avaliação argumentam que o Saeb não pretende criar impactos no interior da escola e que, portanto, tais colocações estariam desqualificando o debate. De fato, ao explicitar os objetivos do Saeb, Locatelli não considera o uso dos resultados para a reformulação das práticas escolares:

"O Saeb tem como objetivos: (i) monitorar a qualidade, a eqüidade e a efetividade do sistema de educação básica; (ii) oferecer, às administrações públicas de educação, informações que thes permitam avaliar seus projetos educacionais e formular programas de melhoria da qualidade de ensino; e (iii) proporcionar aos agentes educacionais e à sociedade informes sobre os resultados dos processos de ensino e dos fatores contextuais a eles associados." (Locatelli, 2002, p. 9)

Se realmente não se pretende utilizar os resultados da avaliação para pensar em ações formuladas a partir de seus resultados, para os diversos níveis de ensino, inclusive a sala de aula, como se pode inferir da citação acima, teremos de enfrentar uma certa contradição interna ao Saeb (ou falta de clareza de seus reais objetivos por parte dos responsáveis pela divulgação dos resultados da avaliação), quando se pensa nos objetivos explicitados, correlacionando-os ao consumo dos resultados. Isso porque, em vez de se limitar a fazer o controle externo, alguns documentos oficiais sugerem que o Saeb é útil para o trabalho em sala de aula, como exemplifica o trecho abaixo:

"Neste relatório, além da escala comum, serão apresentados os níveis interpretados para cada uma das séries, isoladamente, tanto para Lingua Portuguesa, quanto para Matemática. Esta forma de apresentação atende a pedidos de professores de todo o Brasil, servindo para uma análise mais acurada das habilidades já desenvolvidas pelos alunos nos diversos niveis em cada série, possibilitando, ainda, um olhar mais crítico para as competências e as habilidades que já deveriam ter sido, mas não foram construídas nas séries avaliadas." (Brasil, 2002, p. 18)

Ora, ao manifestar tal compromisso para com os professores, apontando-lhes questões que seriam de seu direto interesse, no que diz respeito ao trabalho em sala de aula, os elaboradores do Relatório Final parecem desconsiderar que tais resultados não têm grande divulgação, $\mathrm{e}$ dificilmente chegam à massa dos profissionais que trabalham diretamente na escola.

Apesar das diferentes visões que os eventuais usos e impactos dos resultados do Saeb têm suscitado, a controvérsia sobre os interlocutores do Saeb parece estar localizada em um debate mais amplo acerca da qualidade da gestão do sistema educacional e da avaliação de políticas. Embora imprescindível, essa análise não elucida uma outra dimensão da discussão 
sobre o tema, relacionada à necessidade de (re)definição dos interlocutores da avaliação, tendo em vista uma de suas finalidades: a melhoria de qualidade do ensino.

Acreditando na importância de uma definição mais clara dos usuários da avaliação, é licito questionar quais seriam os limites e potencialidades de uma ampla divulgação do Saeb junto aos professores. Se, por um lado, muitas discussões têm sido realizadas nesse sentido ${ }^{5}$, por outro, caberia investigar, com lastros empíricos, quais são os impactos da divulgação dos resultados nas escolas e como eles são - ou podem ser utilizados. Mesmo porque se uma das pretensões da avaliação é subsidiar a formulação de programas para a melhoria da qualidade de ensino, seria de se esperar que professores fossem, de alguma forma, chamados ao debate sobre a qualidade do ensino. Será possível melhorar a qualidade do ensino sem discutir com os sujeitos que são responsáveis por ela, no cotidiano escolar, os resultados das avaliações? Os professores têm clareza dos parâmetros de qualidade que norteiam o Saeb? Sabem como ela está sendo aferida e quais são os resultados dessa aferição?

Além disso, apesar da polêmica sobre quais seriam os interlocutores da avaliação, o fato é que mesmo que os dados oficiais do Saeb não cheguem às escolas e aos professores de forma sistemática, é de domínio público que alguns resultados são disseminados pelos meios de comunicação que, não raro, fazem uma análise aligeirada e até sensacionalista dos dados. Investigar em que medida os professores se apropriam dessas informações, e as ressignificam, seria de extremo interesse para subsidiar o debate e, conseqüentemente, uma melhor definição dos interlocutores da avaliação.

\section{O SAEB E A AFERIÇÃO DA QUALIDADE DO ENSINO}

É incontestável que a divulgação dos dados do Saeb, nos grandes órgãos de comunicação, faz com que estes se tornem públicos e costuma vir

\footnotetext{
${ }^{5} \mathrm{O}$ debate sobre os aspectos positivos e negativos da divulgação dos resultados tem sido realizado nos meios acadêmicos já há alguns anos e observam-se visões divergentes sobre essa questão. Alguns autores ressaltam a positividade da divulgação dos resultados, tendo em vista a necessidade de transparência das ações públicas em uma gestão democrática; outros se preocupam com os usos dos resultados no ranqueamento entre os Estados, congelamento do currículo, propaganda política, etc. Tais questionamentos, imprescindíveis para o fortalecimento do debate, carecem, a nosso ver, de dados empíricos que subsidiem as argumentações. Pesquisas que procurassem explicitar como as informações chegam às escolas e quais os usos que fazem delas seriam, nesse momento, de extremo interesse para a área de avaliação educacional.
} 
acoplada, não raro, à idéia de medida da qualidade da educação no Brasil. Ou seja, por meio do Saeb poderíamos medir a qualidade da educação e do ensino então praticado. 6

Não deixa de ser interessante apontar como a divulgação e a discussão dos dados desse sistema de avaliação costumam aparecer em veículos de grande divulgação: "Qualidade de ensino caiu entre 1995 e 2001" (Leale, 2002); a respeito da metodologia do exame, outro jornal diz: "O Saeb, realizado a cada dois anos, visa avaliar a qualidade da educação e verificar que fatores interferem no desempenho dos estudantes" e na mesma edição afirma-se que: "Quando são analisados os resultados desde 1995, há uma queda na qualidade do ensino em todas as séries." (Góis, 2002). Poderíamos elencar inúmeros exemplos como esses, não só da mídia impressa, o que não deixa de ser um fato extremamente relevante, por ser, talvez, pelos órgãos de comunicação que a grande massa de professores, por exemplo, tem condições de ter acesso à divulgação dos dados do Saeb.

Admitindo essa premissa, poderíamos, no entanto, perguntar: mas o Saeb não pretenderia apenas medir, digamos, o nível de aprendizagem dos alunos brasileiros em determinadas disciplinas, no caso, Português e Matemática - únicas contempladas nas duas últimas versões do exame - e correlacioná-lo, mediante questionários destinados a diretores, professores e alunos, a determinadas condições extra e intra-escolares que poderiam favorecer ou não a aprendizagem nessas disciplinas? Podemos reduzir essa pretensão à medida da qualidade de ensino? Se essa pretensão for verdadeira, para se identificar estados de "má qualidade", "boa qualidade" e tudo o mais que daí possa derivar, não seria necessário se explicitar o padrão ou parâmetro de qualidade pelos quais julgamentos como esses são feitos?

Para além dessas especulações e das possíveis repercussões da divulgação dos dados do Saeb, vamos aos fatos, ou melhor, à explicitação das pretensões do Saeb tal como se encontra no último relatório geral publicado pelo Inep, referente ao ciclo da avaliação realizado em 2001:

“O Sistema Nacional de Avaliação da Educação Básica (Saeb), criado em 1990, constitui-se em relevante instrumento para subsidiar e induzir políticas orientadas para a melhoria da qualidade da educação brasileira. O Saeb avalia a qualidade,

\footnotetext{
6 É fato que o uso do termo qualidade, em educação, é diversificado e não seria trivial diferenciar, por exemplo, os sentidos e significados de expressões como qualidade da educação e qualidade de ensino. Entretanto, é comum que tais diferenças semânticas não provoquem diferenças significativas ou perceptíveis quanto ao uso que se pretende dar ao termo. Nesse sentido, nesse trabalho, tomaremos as expressões qualidade da educação e qualidade de ensino como sinônimas.
} 
a eqüidade e eficiência do ensino e da aprendizagem no âmbito do ensino fundamental e médio. Aplicado a cada dois anos, utiliza testes e questionários para analisar o desempenho dos alunos e os fatores associados a esse desempenho. Os testes utilizados são elaborados a partir das Matrizes de referência construídas para a avaliação do SAEB, tendo como base as Diretrizes Curriculares Nacionais, a Lei de Diretrizes e Bases da Educação Nacional (LDB) e as propostas curriculares de todos Estados da Federação. (Brasil, 2002, p.12, grifos nossos)

Antes de tudo, o Saeb se propõe, dentre outras coisas, a avaliar a qualidade do ensino e da aprendizagem. Resta saber, ou melhor, deduzir, qual a idéia de qualidade que lhe subsidia a análise. Nesse sentido, a idéia de qualidade não se encontra explicitada no texto. Podemos apenas vislumbrá-la a partir da própria lógica do sistema, de suas matrizes, ou de sua inserção no contexto atual das políticas educacionais, o que não deixa de nos parecer insatisfatório.

Observamos que esse entendimento e uso indiscriminado da expressão qualidade de ensino, além de esboçado nos objetivos do Saeb, como pudemos perceber em seu relatório nacional, também se encontra em outros documentos produzidos pelo Inep ${ }^{7}$ e em falas de pesquisadores do assunto, como a que aparece em uma passagem de texto cujo título, sugestivo, é "Por uma educação de qualidade". No início do referido texto, ao enfatizar que as políticas educacionais do Brasil têm tido, atualmente, como objetivo principal "colocar e manter o aluno na escola", o autor diz que " $A$ melhoria da qualidade de ensino, no sentido da aprendizagem dos alunos, tem sido relegada a um segundo plano" (Klein, 2003, p. 115-120, grifos do autor).

Poderíamos, pois, perguntar: em que sentido um sistema como o Saeb, se propõe a medir a qualidade de ensino? Podemos considerar que as análises dos resultados desse sistema propiciam um diagnóstico fiel da qualidade do ensino atual, tendo em vista o padrão de qualidade subentendido em julgamentos desse tipo? Nos termos dos objetivos do sistema de avaliação, acima descritos, mensurar níveis de aprendizagem, a partir de determinados critérios, é o mesmo que avaliar as práticas de ensino que supostamente produziriam tais aprendizagens?

Para problematizar indagações dessa natureza, pode ser interessante recorrer ao que diz Vianna a propósito da mensuração de "qualidade em educação":

\footnotetext{
7 Como, por exemplo, o documento: “Qualidade da Educação: uma nova leitura do desempenho dos estudantes da $3^{\circ}$ série do Ensino Médio" de janeiro de 2004, disponível no site www.inep.gov.br, em abril de 2004.
} 
"[...] como conceituar qualidade em educação? Será possível uma definição operacional de qualidade em educação a fim de mensurá-la com adequação? O problema precisa ser analisado e discutido com a participação da comunidade educacional e de elementos da sociedade. A medida da qualidade em educação, entretanto, não pode ficar restrita apenas ao desempenho escolar. Necessita, também, verificar outras variáveis que se associam e condicionam o rendimento escolar. O que as crianças fazem na escola, o que os professores procuram transmitir aos seus alunos e o que os livros didáticos apresentam refletem expectativas culturais e educacionais da sociedade, bem como seus valores e seus objetivos sociais e econômicos. Assim, é impositivo verificar em que medida a interação dessas variáveis contribui para a qualidade da educação." (Vianna, 2000, p. 189-190, grifos nossos)

De qualquer forma, o relatório do Saeb e sua divulgação nos dão a idéia de uma suposta fidedignidade na medida de qualidade. E, curiosamente, a idéia de qualidade, nesses termos, permanece sem ser discutida ou, ainda, se reduz à mensuração de determinados níveis de aprendizagem. Se o Saeb busca avaliar qualidade de ensino, ainda que esta não esteja devidamente explicitada, somos levados à formulação de hipóteses sobre qual seria o parâmetro dessa qualidade. Nesses termos, seria mais do que natural conceber que o parâmetro de qualidade desejado seria o das diretrizes curriculares nacionais com sua formulação amparada na expectativa dos alunos adquirirem dadas "competências e habilidades".

Mas podemos reduzir o conceito de qualidade de ensino à aquisição de competências e habilidades? E mais, elas possuem uma formulação adequada ou consensual - para utilizarmos a mesma expressão contida no documento "Matrizes Curriculares de Referência do Saeb" - imune a críticas?

Não pretendemos analisar essa questão como problema semântico ou de busca de uma definição da "verdadeira qualidade de ensino". Inevitavelmente, há muitos usos do termo qualidade em educação, e quanto à discussão de usos de termos como qualidade de ensino ou educação de qualidade não cabe contestação, mas sim sua constatação, uma vez que se percebe seu uso comum e diversificado.

Entretanto, admitir diversos usos de um termo é diferente de discutir quais pressupostos animam suas diversas definições e o tipo de programa prático que estas procuram ensejar8. Desacreditar, por exemplo, que boa parte da clientela escolar, tanto de escolas públicas como das privadas, consideraria como escola de qualidade aquela que mais aprova seus alunos nos exames vestibulares das universidades mais concorridas,

8 Nesse sentido, são de extremo interesse as categorias de análise do discurso educacional, estipuladas por Israel Scheffler (1974), em especial suas definições programáticas. 
seria argumento ocioso. Por outro lado, parece legítimo questionar e discutir um conceito de qualidade nesses termos, ou seja, reduzindo-o ao índice de aprovação que a escola obtém no vestibular.

Da mesma forma, um parâmetro de qualidade que subsidia uma avaliação de importância nacional como o Saeb, norteado pelas diretrizes curriculares e sua fonte inspiradora, que são os PCN's - com todos os seus problemas e limites - pode ser aceito como medida do que se espera de uma educação de qualidade para toda uma nação? Será interessante reduzir o parâmetro de qualidade de educação à aquisição de "competências" e "habilidades", termos esses cujas definições, para além de adesismos ingênuos ou pressões de toda sorte para que sejam utilizados, são pouco ou mal explicitadas?

Parece que grande parte das críticas e observações que se tem feito ao Saeb passam ao largo das questões acima expostas, o que nos causa certa preocupação que se adensa quando identificamos que a decantada fidedignidade da aferição de qualidade é posta em dúvida nos próprios documentos do Saeb, quando são explicitados alguns dos procedimentos de coleta de dados empregados pelo sistema que, no exemplo abaixo, se referem aos questionários respondidos pelos professores e sua correlação com o desempenho dos alunos:

"Deve-se esclarecer que estas análises fazem parte de um primeiro esforço de interpretar as relações entre as práticas pedagógicas dos professores e o desempenho dos alunos. Os resultados encontrados basearam-se nas respostas dos professores e não em observação das práticas pedagógicas em sala de aula. É licito argumentar que o discurso dos professores pode não corresponder com o que efetivamente é ensinado em sala de aula; mais ainda, é possível levantar a hipótese de que muitos professores poderiam responder o questionário de acordo com o que interpretam ser o padrão de resposta mais adequado." (Brasil, 2002, p. 137)

Não perdemos de vista que um sistema de avaliação como o Saeb pode ter gerado uma preocupação, por parte dos gestores de sistemas educacionais, em torno da avaliação do que vem sendo produzido em seus respectivos sistemas, no que se refere às aprendizagens dos alunos, algo que não deixa de ser bastante interessante e necessário ao trabalho escolar, este entendido como prática social pública. Contudo, fica a indagação: poderá o Saeb subsidiar um debate mais qualificado e rigoroso em torno da qualidade de ensino que pretendemos oferecer e verificar em nossas escolas? Será que o Saeb não está sendo o elemento mais contundente de aceitação de um parâmetro de qualidade discutível, a partir dos termos em que se formularam os PCN's e as conseqüentes Matrizes de Referência? 
Uma avaliação, como a que faz o Saeb, não age por si, embora não raro ganhe ares de ser, ela própria, a responsável pela execução e formulação de políticas. Tais questões referem-se a interesses que se ambientam e se desenvolvem no debate político acerca dos usos da avaliação, não sendo, portanto, questão meramente técnica como muitos podem supor. Assim, avaliar os pressupostos e pretensões de avaliações sistêmicas como o Saeb, como também o uso de seus resultados, parece ser um dos principais desafios situados nesse debate, que apenas se inicia e que, ao que tudo indica, não tem hora para acabar.

\section{REFERÊNCIAS BIBLIOGRÁFICAS}

AFONSO, Almerindo J. Avaliação Educacional: regulação e emancipação. São Paulo: Cortez, 2000.

ARCAS, Paulo Henrique. Avaliação da Aprendizagem no Regime de Progressão Continuada: o que dizem os alunos. São Paulo, 2003. Dissertação (mestr.) Universidade de São Paulo/ Faculdade de Educação.

AZANHA, José Mário P. Parâmetros Curriculares Nacionais e autonomia da escola. 2001. Disponível em: http://hottopos.com/-International Studies on Law and Education Publishers. Acesso em: 01/04/2004.

BONAMINO, Alicia C. Tempos de avaliação educacional: o Saeb, seus agentes, referências e tendências. Rio de Janeiro: Quartet, 2002.

BRASIL. Ministério da Educação e Cultura. Saeb 2001: Relatório Nacional. Brasília, Inep, 2002. 303p.

BRASIL. Ministério da Educação e Cultura. Matrizes Curriculares de Referência do Saeb, 1999.

BRASIL. Ministério da Educação e Cultura. SAEB: Metodologia Utilizada. Disponível em: http:/ /www.inep.gov.br. Acesso em: 25/04/2004. 
BRUNO, Lúcia. Reorganização Econômica, Reforma do Estado e Educação. In: HIDALGO, Ângela M.; SILVA, Ileizi. Educação e Estado: as mudanças nos sistemas de ensino do Brasil e do Paraná na década de 90. Londrina: UEL, 2001.

FREITAS, Luiz Carlos de. Avaliação: construindo o campo e a crítica. Florianópolis: Insular, 2002.

Implicações conceituais para uma prática avaliativa. Disponível em: http://www.prg.unicamp.br/implicacoes_conceituais_pratica_aval_luiz_ carlos.htm. Acesso em: 14/10/2004.

GÓIS, Antonio. Exame mostra queda de nota na $4^{\mathrm{a}}$ série. Folha de S. Paulo, São Paulo, 6/12/2002, c. 1, p.14.

Teste irá avaliar alfabetização na segunda série. Disponível em: http://www1.folha.uol.com.br/folha/educacao/ult305u15960.shtml. Acesso em: 29/08/2004.

KLEIN, Rubem. Por uma Educação de Qualidade. Avaliação e Políticas públicas em educação. Ensaio, v. 11, n. 38, p.115 -120, jan./mar. 2003.

LEALE, Francisco. Qualidade de ensino caiu entre 1995 e 2001. O Globo, Rio de Janeiro, 6/12/2002, p.18.

LOCATELLI, Iza. Construção de instrumentos para a avaliação de larga escala e indicadores de rendimento: o modelo SAEB. Estudos em Avaliação Educacional, São Paulo: FCC, n. 25, p. 3-21, jan./jun. 2002.

OLIVEIRA, Romualdo P. Reformas educativas no Brasil na década de 90. In: CATANI, Afrânio M.; OLIVEIRA, Romualdo P. de. Reformas educacionais no Brasil em Portugal e no Brasil. Belo Horizonte: Autêntica, 2000.

A municipalização do ensino no Brasil. In: OLIVEIRA, Dalila Andrade (org.). Gestão Democrática da Escola. Rio de Janeiro: Vozes, 1997. p. 264-280. 
SÁ PESTANA, Maria Inês G. de et al. Matrizes Curriculares de Referência para o Saeb. Brasília: Instituto Nacional de Estudos e Pesquisas Educacionais, 1999. 134 p.

SANCHEZ, Ana. Os Parâmetros Curriculares Nacionais e as críticas apresentadas. Pátio, n. 0, Porto Alegre: Artes Médicas, 1997. p. 13-18.

SANTOS, Lucíola L. de C. P. Políticas públicas para o ensino fundamental: parâmetros curriculares nacionais e sistema nacional de avaliação (Saeb). Educação e Sociedade, v. 23, n.80, p.346-367, set. 2002.

SCHEFFLER, Israel. A linguagem da educação. São Paulo: Saraiva, 1974.

SOARES, José Francisco. Construindo o campo e a crítica: o debate. In: FREITAS, Luiz Carlos de. Avaliação: construindo o campo e a crítica. Florianópolis: Insular, 2002. p. 99 -214.

SOUSA, Sandra M. Z. L. Avaliação do rendimento escolar como instrumento de gestão educacional. In: OLIVEIRA, Dalila Andrade (org.). Gestão Democrática da Escola. Rio de Janeiro: Vozes, 1997. p. 264-280.

- Possíveis impactos das políticas de avaliação no currículo escolar. São Paulo: Fundação Carlos Chagas, Cadernos de Pesquisa, n. 119, p. 175-190, jul. 2003.

educacional. Mimeo, 2003.

TIANA, Alejandro. Anais do Seminário Internacional de Avaliação Educacional, Brasília: MEC/Inep, 1998.

TOMMASI, Lívia de; WARDE, Miriam Jorge; HADDAD, Sérgio (orgs). O banco mundial e as políticas educacionais. São Paulo: Cortez, 1998. 279 p.

TORRES, Rosa Maria. Tendências da formação docente nos anos 90. In: WARDE, M. (org.). Novas politicas educacionais: críticas e perspectivas. São Paulo: PUC, 1998. p. 173-191. 
VIANNA, Heraldo M. Avaliação Educacional: teoria, planejamento, modelos. São Paulo: Ibrasa, 2000.

Avaliando a avaliação - da prática à pesquisa. São Paulo: Fundação Carlos Chagas. Estudos em Avaliação Educacional, n. 5, p. 55-64, jan./jun.1992.

Avaliações Nacionais em Larga Escala: análises e propostas. São Paulo: Fundação Carlos Chagas, 2003. (Textos FCC, 23)

VIANNA, Heraldo M. Construindo o campo e a crítica: o debate. In: FREITAS, Luiz Carlos de. Avaliação: construindo o campo e a crítica. Florianópolis: Insular, 2002. p. 99-214.

Recebido em: dezembro 2004

Aprovado para publicação em: janeiro 2005 